\title{
Comparing the Liquid Heparin Syringe with Dry Bound Heparin Syringe for Blood Gas Analysis
}

\author{
Manoj Kumar Sahu ${ }^{1}$ Seshagiribabu Yagani ${ }^{1}$ \\ Shiv Kumar Choudhary ${ }^{1}$ \\ ${ }^{1}$ Department of Cardiothoracic and Vascular Surgery, All India \\ Institute of Medical Sciences, Ansari Nagar, New Delhi, India
}

\author{
Dharmraj Singh ${ }^{1} \quad$ Umed Singh ${ }^{1} \quad$ Sarvesh Pal Singh ${ }^{1}$
}

Address for correspondence Manoj Kumar Sahu, MD, DNB, Department of Cardiothoracic and Vascular Surgery, CTVS Office, 7th Floor, CN Centre, All India Institute of Medical Sciences, New Delhi 110029, India (e-mail: drmanojsahu@gmail.com).

\begin{abstract}
Keywords

- blood gas analysis

- dry bound heparin syringe

- liquid heparin syringe

Background Blood gas (BG) analysis is routine today for patient management in intensive care units. Accurate analysis of different parameters in the BG is essential for managing critical patients. Errors in BG analysis can happen at many levels, with one of them being at sampling and heparinization. We compared self-prepared heparinized syringes rinsed with liquid heparin (LH) and the standard commercially available syringes with dry bound heparin (DBH) for arterial BG analysis of postoperative cardiac surgical patients.

Methods This prospective observational study was conducted in 100 consecutive adult cardiac surgical patients in the cardiac surgical intensive care unit. Paired samples were collected, analyzed immediately, and statistically compared for $\mathrm{pH}$, partial pressure of arterial oxygen $\left(\mathrm{pO}_{2}\right)$, partial pressure of arterial carbon dioxide $\left(\mathrm{pCO}_{2}\right)$, oxyhemoglobin saturation $\left(\mathrm{SaO}_{2}\right), \mathrm{HCO}, \mathrm{Na}^{+}, \mathrm{K}^{+}, \mathrm{Cl}^{-}, \mathrm{Ca}^{2+}, \mathrm{Mg}^{2+}$, base excess (BE), hemoglobin $(\mathrm{Hb})$, hematocrit, glucose, and lactate. Paired parameters were compared and agreement was evaluated using Bland-Altman difference plots. The $95 \%$ limits of absolute agreement (LOA) were compared with total allowable error (TEa).

Results The BG parameters analyzed by two types of heparinized (LH and DBH) syringes were found to be comparable with a negligible mean difference and had an agreement outside the TEa of $8 \%$ for $\mathrm{pO}_{2}, \mathrm{pCO}_{2}$, and hematocrit, $7 \%$ for $\mathrm{BE}, 6 \%$ for $\mathrm{Mg}^{2+}$, $5 \%$ for $\mathrm{K}^{+}, \mathrm{Ca}^{2+}$, and lactate, $4 \%$ for $\mathrm{HCO}^{2}$ and $\mathrm{Na}^{+}, 3 \%$ for $\mathrm{pH}, \mathrm{Cl}^{-}, \mathrm{Hb}$, and glucose, and zero for $\mathrm{SaO}_{2}$. The two types of syringes did not show clinically relevant discrepancies among many different parameters as per LOA and TEa limits.

Conclusion In this study, we found that the BG parameters-respiratory, metabolic, and electrolytes-were comparable between the two types of syringes used for sampling. Unlike some previous studies, we did not find statistically significant differences among these analytes, which might have been due to appropriate self-preparation of heparin syringes.
\end{abstract}

\section{Introduction}

Blood gas (BG) analysis is an essential part of the diagnosis and management of alteration in respiratory and metabolic parameters of the body. It has been an important tool for emergency physicians, anesthesiologists, and intensivists to understand and manage the critically ill patients. Faster and accurate results are important to form rule-out and rule-in strategies in these sick patients. The usefulness of this diagnostic tool is dependent on the accuracy of sampling, volume of syringe used, amount of sample, type and amount
DOI https://doi.org/ $10.1055 / \mathrm{s}-0040-1709624$ ISSN 2457-0206.
License terms

(요 (1) $\circledast$ 
of heparin used, storage, transport, and timing of analysis to correctly interpret the results. However, many preanalytical errors are possible while collecting blood samples, leading to erroneous BG values. ${ }^{1}$ This may have an influence on the further management of extremely vulnerable patients.

Although the guidelines by the National Committee for Clinical \& Laboratory Standards Institute (CLSI), Wayne, Pennsylvania, United States, suggested the use of commercially prepared dry bound heparin (DBH) syringes (which avoids dilution due to the use of dried heparin), still self-prepared liquid heparin (LH) syringes are used in many emergency and intensive care units (ICUs) for BG analysis to curtail heavy economic burden in high-volume hospitals with lack of resource., ${ }^{2,3}$ LH may have many effects on BG analysis due to its dilutional effect on plasma, thereby altering some parameters such as partial pressure of arterial carbon dioxide $\left(\mathrm{pCO}_{2}\right)$ and electrolytes. By binding to positive ions such as $\mathrm{Ca}^{2+}, \mathrm{Na}^{+}$, and $\mathrm{K}^{+}$, $\mathrm{LH}$ may result in falsely low values. ${ }^{4}$ In addition, the heparin sodium or heparin calcium salts may have composition effects on BG analysis, leading to positive bias. ${ }^{4}$ There are no universally accepted guidelines or recommendations for the manually prepared heparinized syringes for sampling, and this remains a nonstandardized method among many ICUs. ${ }^{5}$ Hence, our study aimed to compare LH and DBH syringes in arterial BG analysis of postoperative adult cardiac surgical patients in our ICU.

\section{Material and Methods}

This prospective observational study was conducted in a cohort of adult patients older than 18 years admitted to the cardiac surgical ICU of a high-volume tertiary care teaching hospital. The study was conducted during a 3-month period from April 2019 to June 2019 after obtaining ethics approval from the institute. Paired samples were collected from 100 consecutive adults who underwent open-heart surgeries electively and admitted to the ICU for postoperative management. Informed consent was invariably obtained from all the patients for ICU management, including blood sampling for different laboratory tests including arterial BG analysis. One paired sample was taken from each patient at a point of time on the second postoperative day, when the patients have become fully clinically, hemodynamically, and metabolically (from the last BG analysis) stable, and ready to be discharged from ICU. Samples were taken from the existing invasive arterial lines (after discarding double the standard dead space volume) placed during surgery, and patients were not punctured separately for drawing arterial blood. BG analysis was performed at the same time soon after drawing and mixing the blood with heparin in the sampling syringes (within 60 seconds), without any waiting period or transport, as BG machines are installed in our ICU.

\section{Study Syringes Details}

- Type 1 syringe was a conventional 2-mL syringe (Solo-Med plastic hypodermic syringes, Becton Dickinson India Pvt. Ltd., Haryana, India) with a needle (24-G, 1-inch) containing the smallest measurable division of $0.01 \mathrm{~mL}$. Type 1 syringes were self-prepared by first filling the barrel of the syringe until $0.5-\mathrm{mL}$ (2,500 units of heparin) marking and then flushing out all the LH solution and air four times so that no visible LH solution was left in the syringe barrel or hub. LH solution (Hepaglan-25) derived from gut mucosa, containing 5,000 IU/ml strength of heparin (Gland Pharma Limited, Telangana, India), was used for the preparation of Type 1 syringe. The analysis of LH solution by the same BG analyzer revealed $\mathrm{pH}$ of 7.40, $\mathrm{pCO}_{2}$ of $3.8 \mathrm{~mm} \mathrm{Hg}, \mathrm{pO}_{2}$ of $111.9 \mathrm{~mm} \mathrm{Hg}$, glucose of $0 \mathrm{mg} / \mathrm{dL}, \mathrm{SO}_{2}$ of $98.7 \%$, base excess (BE)-b of $-17.2 \mathrm{mmol} / \mathrm{L}$, $\mathrm{HCO}^{3}$ of $2.4 \mathrm{mmol} / \mathrm{L}$, and lactate, $\mathrm{Na}, \mathrm{K}, \mathrm{Cl}, \mathrm{Ca}, \mathrm{Mg}$ of $0 \mathrm{mmol} / \mathrm{L}$ as $\mathrm{LH}$ in syringe get in equilibrium with the air.

- Type 2 syringes are commercially prepared electrolyte DBH 3-mL syringes without a needle (Smith Medical ASD Inc., Keene, New Hampshire, United States) containing the smallest measurable division of $0.01 \mathrm{~mL}$. These syringes contain approximately 23.57 IU units of heparin per milliliter capacity, and the coated material is dry lithium heparin.

Type 1 syringes were prepared just before the sample collection. All the paired arterial samples were collected in type 1 and type 2 syringes till $1-\mathrm{mL}$ mark in the syringe. The samplings were performed at bedside by the same trained senior resident in all the study patients. Meticulous precautions were taken to mix the blood with heparin well while preventing hemolysis and formation of air bubbles by gently rolling the blood-filled syringe between the palms and finally pushing the piston slowly upward when the nozzle is open to atmosphere in an upward direction and caped as soon as the blood reaches the tip. Paired samples were analyzed immediately after collection by one BG analyzer with star profile and cartridge system (pHOx Ultra, NOVA Biomedical, Waltham, Massachusetts, United States) installed in the ICU. This BG analyzer calibrated automatically every 4 hourly and was checked weekly with control solutions. Statistical Analysis

All BG parameters were expressed as mean and standard deviation (SD). The Wilcoxon matched-pair signed-rank test was used to compare paired variables. It compared the bias (mean difference) and precision (SD of bias) of type $1(\mathrm{LH})$ syringe versus type 2 (DBH) syringe sampling for BG analysis. Bland-Altman difference plots were used to assess and calculate $95 \%$ limits of agreement (LOA). LOA of BG analytes were then compared with the total allowable error (TEa). TEa is the total amount error in a test that is medically, administratively, and legally acceptable. The proportion of sample beyond TEa \% was then calculated, and TEa $<10 \%$ is considered as statistically insignificant.

\section{Results}

A total of 100 consecutive postoperative cardiac surgical patients were included in our study, and the population comprised middle-aged adults with a mean age of $40.13 \pm 21.91$ (mean \pm SD) and mixture of both genders 
(male:female $=68: 32$ ). A total of 200 samples were collected from these patients (100 samples each in two different types of heparinized syringes) and analyzed. The pairwise comparison between samples collected in type 1 (LH) and type 2 (DBH) syringes, such as mean with SD, mean difference, 95\% LOA, proportion beyond TEa \%, are shown in - Table 1.

Results of the present study showed that samplings in type $1(\mathrm{LH})$ and type 2 (DBH) syringes were comparable with a negligible mean difference. The LOA and sample outside the TEa was $8 \%$ for $\mathrm{pO}_{2}, \mathrm{pCO}_{2}$, and hematocrit (Hct), $7 \%$ for $\mathrm{BE}, 6 \%$ for magnesium $\left(\mathrm{Mg}^{2+}\right), 5 \%$ for potassium $\left(\mathrm{K}^{+}\right)$, calcium $\left(\mathrm{Ca}^{2+}\right)$, and lactate, $4 \%$ for bicarbonate (HCO) and sodium $\left(\mathrm{Na}^{+}\right), 3 \%$ for $\mathrm{pH}$, chloride $\left(\mathrm{Cl}^{-}\right)$, hemoglobin $(\mathrm{Hb})$, and glucose, and $0 \%$ for oxyhemoglobin saturation $\left(\mathrm{SaO}_{2}\right)$. Figures from 1 to 8 shows the Bland-Altman plots for different BG analytes such as $\mathrm{pH}\left(-\right.$ Fig. 1), $\mathrm{pCO}_{2}$ ( - Fig. 2), calcium ( - Fig. 3), magnesium ( - Fig. 4), BE ( - Fig. 5), lactate ( - Fig. 6), Hct ( - Fig. 7 ), and glucose ( - Fig. 8) individually.

\section{Discussion}

Unfractionated heparin (LH sodium) is widely used and the only suitable anticoagulant for blood sampling for BG analysis. Although an error is quite possible during BG analysis due to the variability of sample volume, dilution, binding, and combining effects of $\mathrm{LH}$, such errors were generally thought to be of theoretical but may be of practical importance and still LH is anticoagulant of choice for BG sampling in many ICUs. ${ }^{1}$ The World Health Organization mentioned that 8 to $12 \mathrm{IU} / \mathrm{mL}$ of $\mathrm{LH}$ should be used in BG analysis, but the exact quantification is not possible in many situations in this LH method, which may lead to errors in BG analysis, ${ }^{5}$ although it is cost-effective and readily mixes up with blood. ${ }^{6}$ Many studies reported that preanalytic errors are the most common form of errors in BG analysis and include hemolysis, effect of temperature, use of plastic syringes, presence of air bubble, delay in sample transport, dilution effects of $\mathrm{LH}$, manufacturing differences among syringe preparation, microclotting in the sample, and error in BG analyzer. ${ }^{7-9}$

In our study, we compared the effects of heparin on BG parameters between customized self-prepared LH syringes (type 1 ) and commercially available DBH syringe (type 2) in adult patients in cardiac surgical ICU because they represented two commonly witnessed practices of syringes at our institute.

In this study, all the respiratory parameters such as a $\mathrm{pO}_{2}, \mathrm{pCO}_{2}$, and $\mathrm{SaO}_{2}$ decreased in the $\mathrm{LH}$ group than the DBH group but did not show statistically significant difference and had narrow LOA, with TEa limits of sample of $8 \%$ for $\mathrm{pO}_{2}$ and $\mathrm{pCO}_{2}$ and zero for $\mathrm{SaO}_{2}$, and results did not show clinical significance between the two groups. Very minimal mean difference was found between the two groups for $\mathrm{pH}$ ( - Fig. 1) and only $3 \%$ samples were displaced outside the TEa limits. Hutchison et al and Ordog et al studied the effects of increasing LH on BG analysis and showed that $\mathrm{pH}$ value was not affected till $40 \%$ dilution of blood samples, but the values of $\mathrm{pCO}_{2}$, HCOshowed an inverse relation as LH volume. ${ }^{10,11}$ This may be due to the buffering effects of the oxyhemoglobin, plasma proteins, and changes in $\mathrm{pCO}_{2}$ and $\mathrm{HCO}$, and could not probably be due to heparin salts. ${ }^{10,11}$

Table 1 Comparison of different blood gas parameters between two different sampling methods (LH and DBH groups)

\begin{tabular}{|c|c|c|c|c|c|}
\hline Parameters & LH, mean (SD) & $\mathrm{DBH}$, mean (SD) & Mean bias & $95 \%$ LOA & $\begin{array}{l}\text { Proportion, } \\
\text { beyond TEa \% }\end{array}$ \\
\hline $\mathrm{pH}$ & $7.41(0.064)$ & $7.41(0.06)$ & -0.003 & -0.033 to 0.028 & 3 \\
\hline $\mathrm{pCO}_{2}(\mathrm{~mm} \mathrm{Hg})$ & $32.59(5.50)$ & $32.879(5.50)$ & -3.084 & -24.217 to 18.049 & 8 \\
\hline $\mathrm{pO}_{2}(\mathrm{~mm} \mathrm{Hg})$ & $157.46(68.34)$ & $160.54(68.34)$ & -0.272 & -4.555 to 4.011 & 8 \\
\hline $\mathrm{SaO}_{2} \%$ & $98.46(2.53)$ & $98.66(2.43)$ & 0 & 0.000 to 0.000 & 0 \\
\hline $\mathrm{HCO}^{3-}(\mathrm{mmol} / \mathrm{L})$ & $20.72(3.39)$ & $21.20(3.39)$ & -0.196 & -1.609 to 1.217 & 4 \\
\hline $\mathrm{Na}^{+}(\mathrm{mmol} / \mathrm{L})$ & $138.57(5.31)$ & $139.08(5.31)$ & -0.511 & -4.366 to 3.344 & 4 \\
\hline $\mathrm{K}^{+}(\mathrm{mmol} / \mathrm{L})$ & $3.85(0.57)$ & $3.95(0.57)$ & -0.098 & -0.565 to 0.368 & 5 \\
\hline $\mathrm{Cl}^{-}(\mathrm{mmol} / \mathrm{L})$ & $107.39(5.40)$ & $109.07(5.55)$ & -1.676 & -6.531 to 3.179 & 3 \\
\hline $\left.\mathrm{Ca}^{2+} \mathrm{mmol} / \mathrm{L}\right)$ & $1.08(0.12)$ & $1.22(0.10)$ & -0.137 & -0.362 to 0.088 & 5 \\
\hline $\mathrm{Mg}^{2+}(\mathrm{mmol} / \mathrm{L})$ & $0.58(0.19)$ & $0.67(0.19)$ & -0.086 & -0.252 to 0.081 & 6 \\
\hline $\mathrm{BE}(\mathrm{mmol} / \mathrm{L})$ & $-2.62(3.55)$ & $-2.27(3.61)$ & -0.350 & -2.410 to 1.710 & 7 \\
\hline $\mathrm{Hb}(\mathrm{gm} / \mathrm{dL})$ & $11.99(1.83)$ & $11.98(1.91)$ & 0.009 & -1.783 to 1.801 & 3 \\
\hline $\mathrm{Hct}$ & $36.48(5.39)$ & $36.26(5.60)$ & 0.220 & -4.337 to 4.777 & 8 \\
\hline Glucose (mg/dL) & $150.90(54.18)$ & $157.55(59.31)$ & -6.650 & -42.655 to 29.355 & 3 \\
\hline Lactate (mmol/L) & $1.98(1.60)$ & $2.12(1.72)$ & -0.148 & -0.718 to 0.422 & 5 \\
\hline
\end{tabular}

Abbreviations: Ca, calcium; BE, base excess; DBH, dry bound heparin; $\mathrm{Hb}$, hemoglobin; $\mathrm{HCO}^{3}$, bicarbonate; Hct, hematocrit; $\mathrm{K}$, potassium; $\mathrm{LH}$, liquid heparin; Mg, magnesium; Na, sodium; SD, standard deviation.

Descriptive statistics, mean with SD, mean bias, $95 \%$ limits of agreement (LOA), proportion of sample beyond TEa \%. 


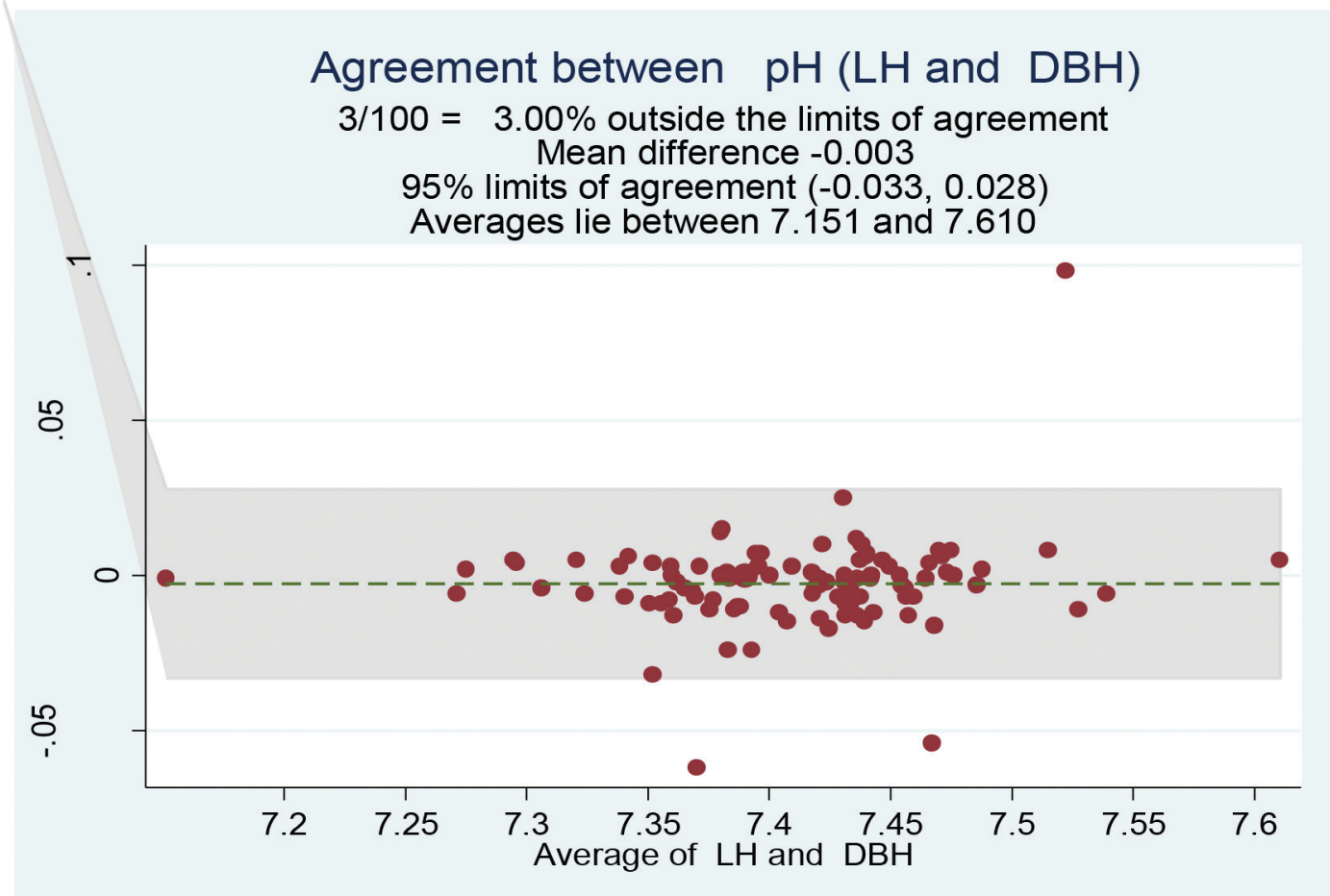

Fig. 1 Bland-Altman plot of pH for the LH group was comparable with that of the DBH group. DBH, dry bound heparin; LH, liquid heparin.

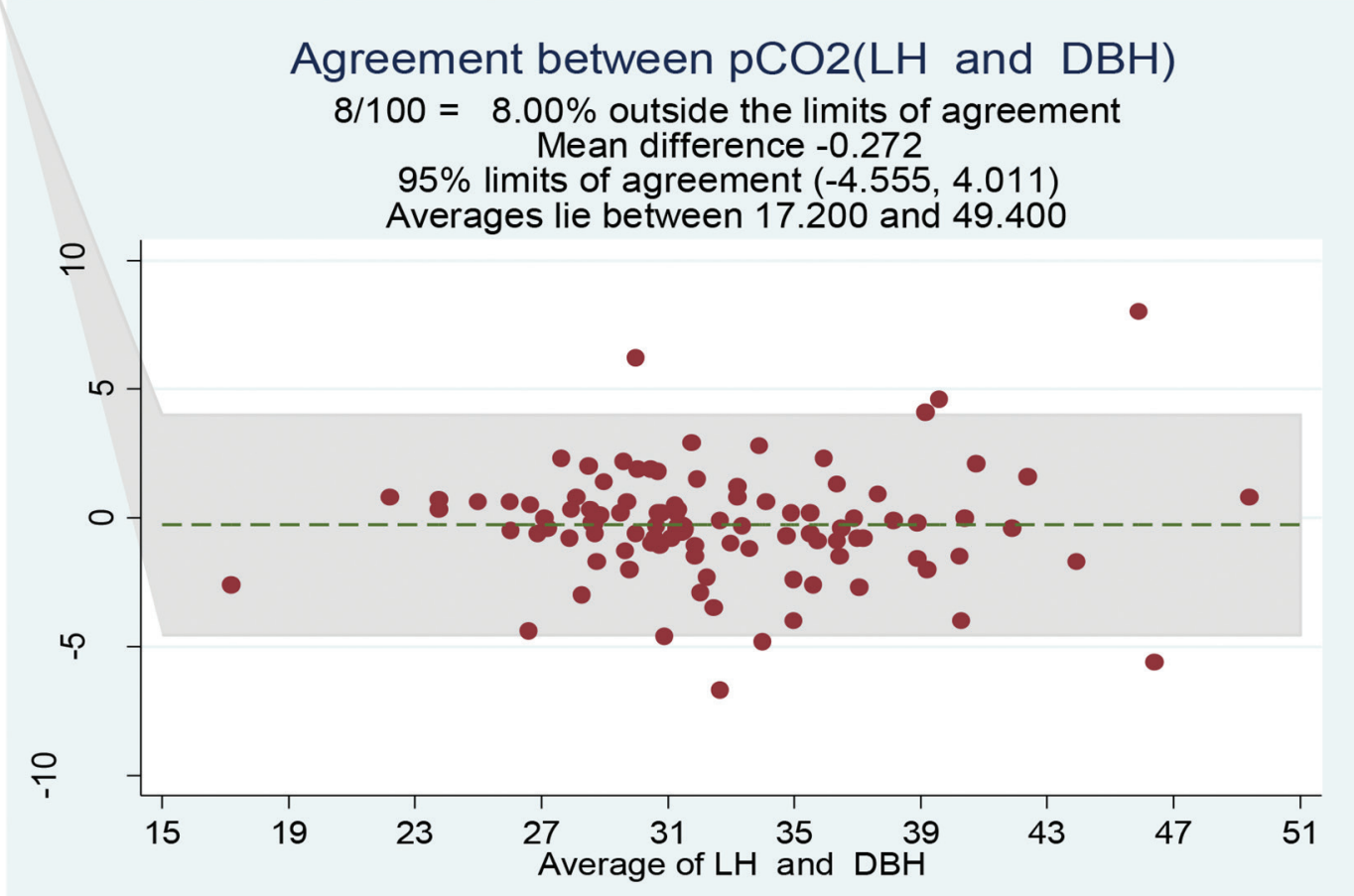

Fig. 2 Bland-Altman plot of partial pressure of carbon dioxide $(\mathrm{mm} \mathrm{Hg})$ for the liquid heparin group was comparable with that of the DBH group. DBH, dry bound heparin; LH, liquid heparin. DBH, dry bound heparin; LH, liquid heparin.

In this study, we observed that all electrolytes were lower in the LH sampling group when compared with the DBH group, but the mean difference, LOA, and proportion of TEa beyond limits followed this order, but all were statistically insignificant: $\mathrm{Mg}^{2+}$ followed by $\mathrm{K}^{+}, \mathrm{Ca}^{2+}$, and, finally, $\mathrm{Na}^{+}$and $\mathrm{Cl}^{-}$. Shin et al observed that $\mathrm{LH}$ anticoagulant produces more negative bias on $\mathrm{Mg}^{2+}$ than $\mathrm{Ca}^{2+}$, and results were similar to our study. ${ }^{12}$ But Chantler and 


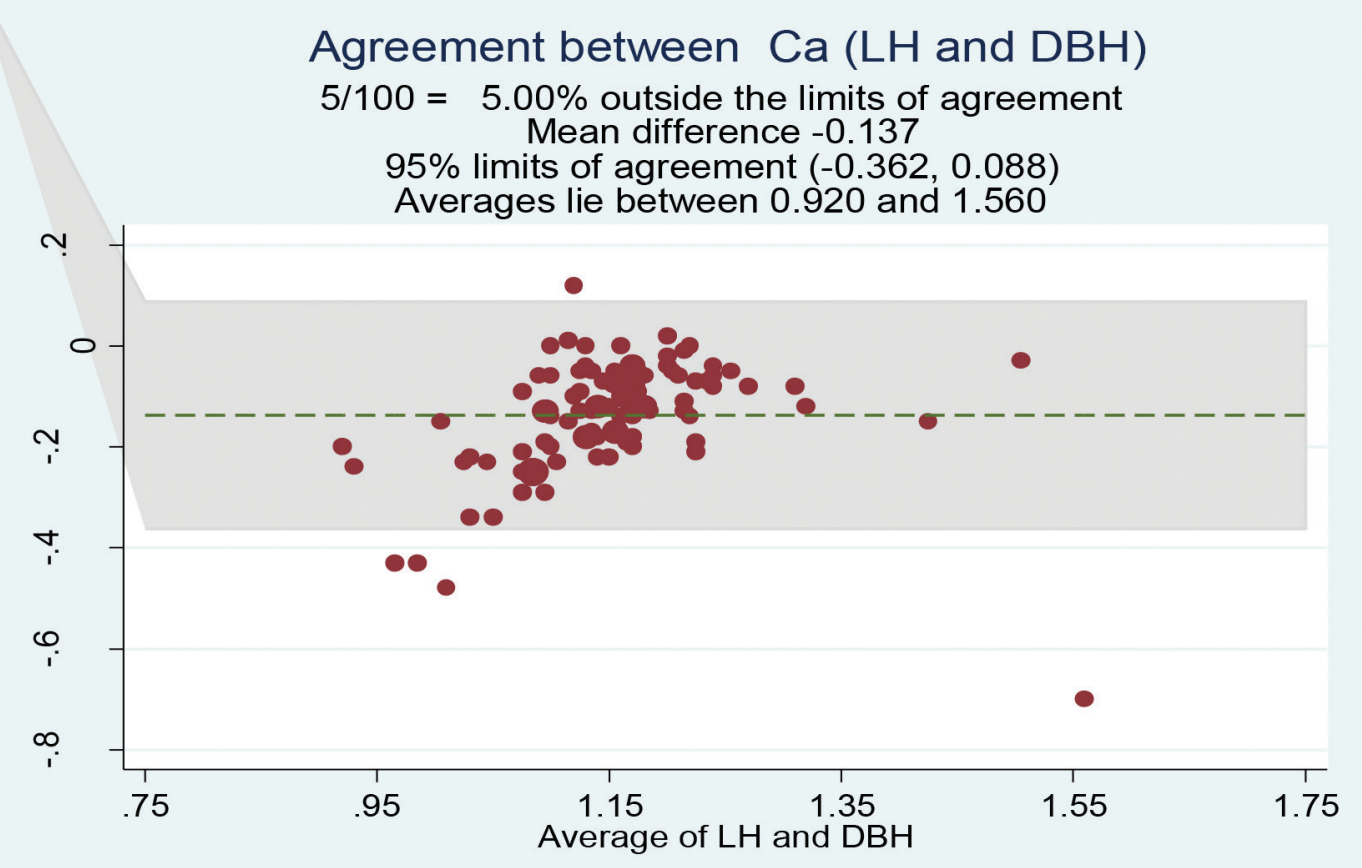

Fig. 3 Bland-Altman plot of calcium (mmol/L) for the LH group compared with that of the DBH group. DBH, dry bound heparin; LH, liquid heparin.

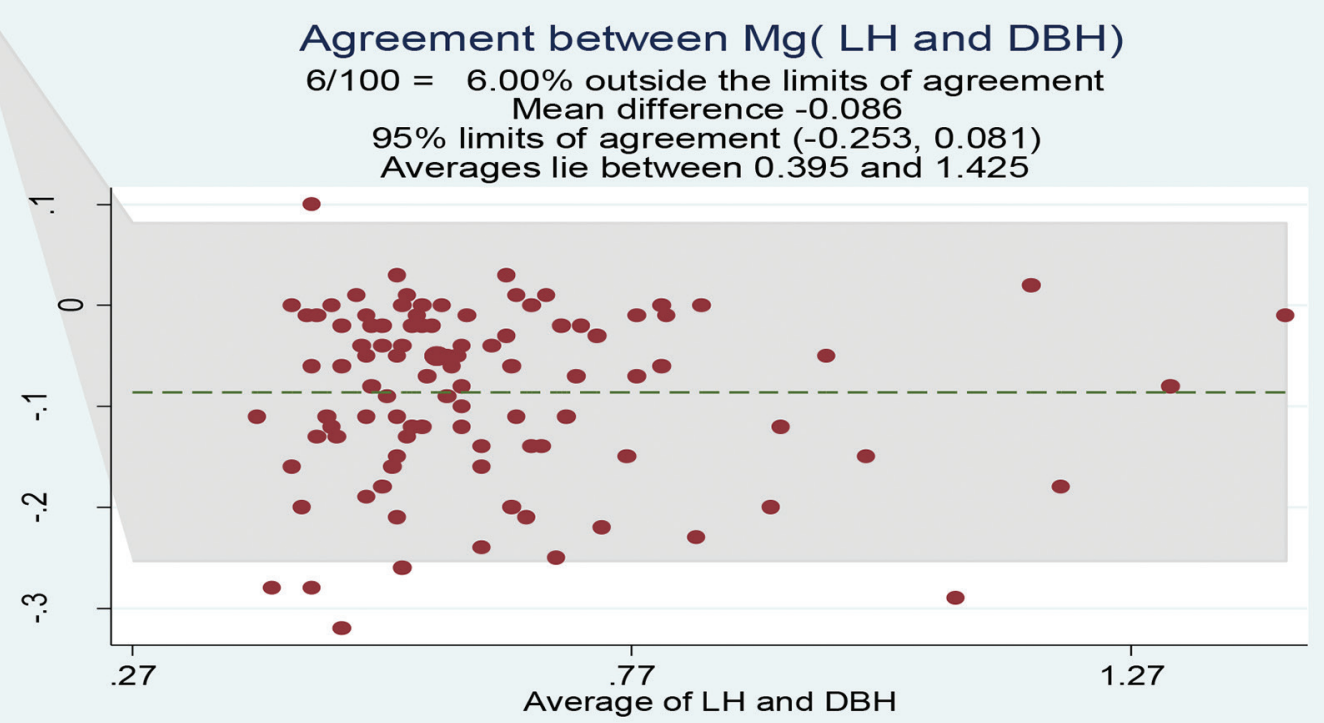

Fig. 4 Bland-Altman plot of magnesium ( $\mathrm{mmol} / \mathrm{L}$ ) for the LH group was comparable with that of the DBH group. DBH, dry bound heparin; LH, liquid heparin.

Cox found a good correlation between LH and DBH in their study. ${ }^{13}$

Until now, no study has analyzed and compared all electrolytes between both types of sampling in cardiac surgical intensive care settings in the adult population. Our study results of electrolytes were comparable with previous studies that showed that excessive heparin lead to an underestimation of positively charged ions such as $\mathrm{K}^{+}, \mathrm{Ca}^{2+}$, and $\mathrm{Na}^{+}$ due to the dilutional and direct binding effects of LH syringe group. ${ }^{12,14,15}$ Chhapola et al and Morimatsu et al in their studies compared the point-of-care testing using heparinized syringe and central laboratory nonheparinized testing and revealed that the decreased levels of $\mathrm{K}^{+}$and $\mathrm{Na}^{+}$in the heparin group may be due to the dilution effects. ${ }^{15,16}$ Similar to previous studies, $\mathrm{Cl}^{-}$came out to be the least affected ion with the least mean difference, with only 3\% beyond TEa limits in our study too. However, all electrolytes are statistically comparable in the LH and DBH groups. 


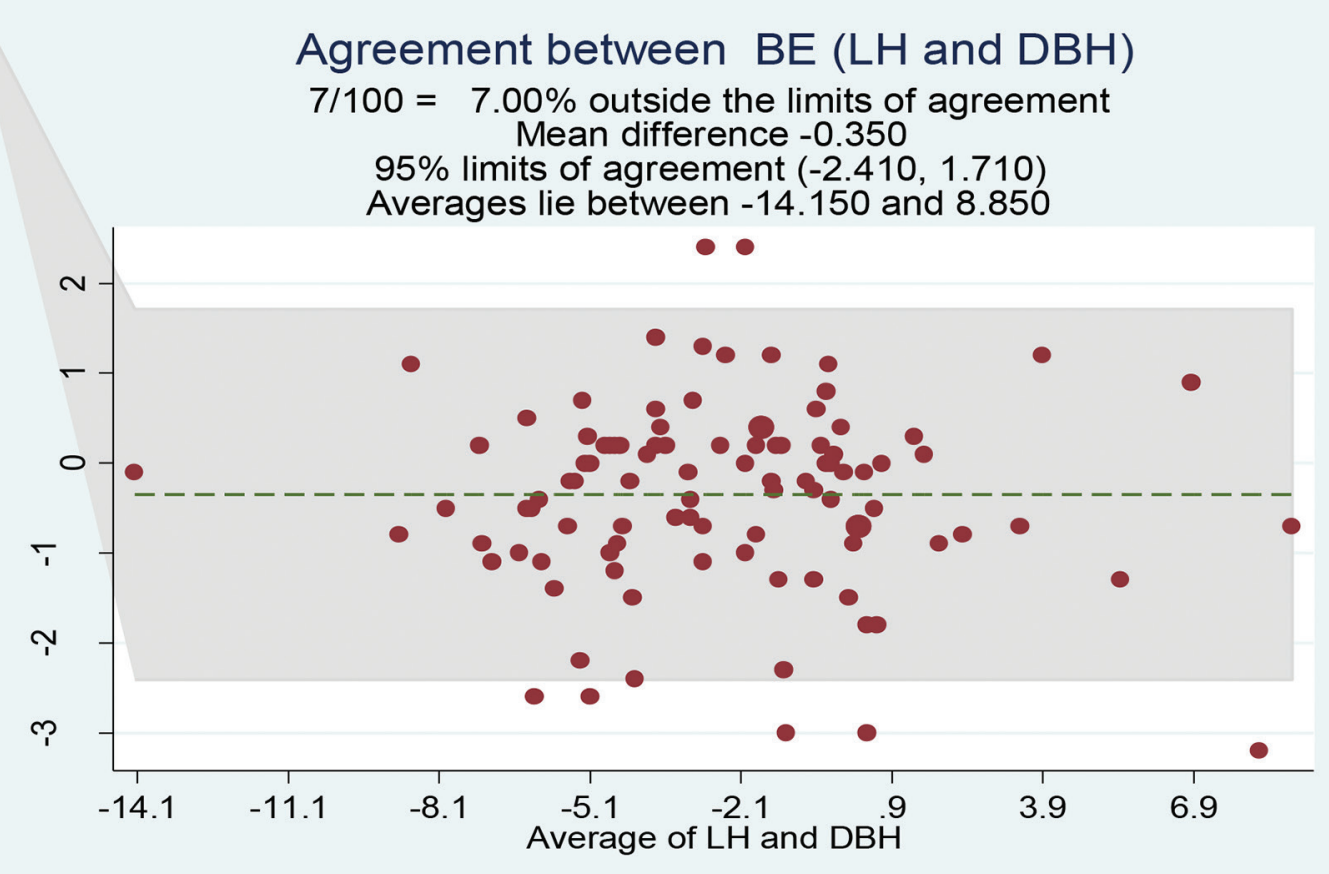

Fig. 5 Bland-Altman plot of BE (mmol/L) for the LH group was comparable with that of the DBH group. DBH, dry bound heparin; LH, liquid heparin.

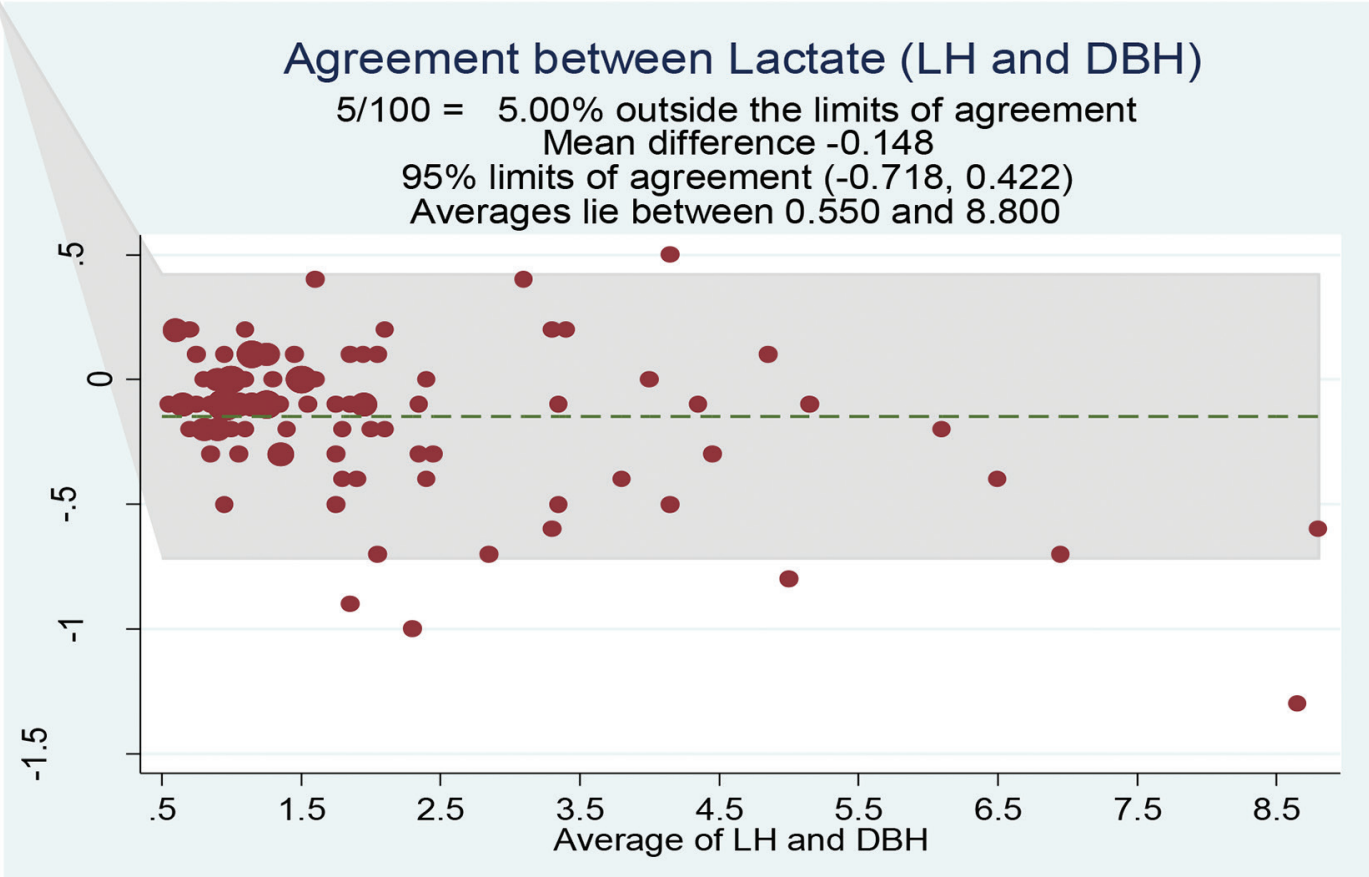

Fig. 6 Bland-Altman plot of lactate (mmol/L) for the LH group was comparable with that of the DBH group. DBH, dry bound heparin; LH, liquid heparin.

Sandler and Goldstein showed in their results that $\mathrm{pCO}_{2}$, $\mathrm{K}^{+}, \mathrm{Na}^{+}, \mathrm{Ca}^{2+}$, and $\mathrm{Hb}$ were falling $>20 \%$ beyond the total allowable error, and $\mathrm{Ca}^{2+}$ and $\mathrm{Na}^{+}$results were most affected in the $5,000 \mathrm{IU} / \mathrm{mL}$ group of sample than the $1,000 \mathrm{IU} / \mathrm{mL}$ cohort group. ${ }^{17}$ In our customized manual syringe preparation for regular sampling for $B G$ analysis, we use 2,500 units $(0.5 \mathrm{~mL})$ of heparin to rinse 2-mL syringes, which seemed to be most appropriate without affecting the results of respiratory, metabolic, and electrolyte analytes when compared with the standard commercially prepared DBH syringes.

As per our study, though the lactate levels increased in the LH group than the DBH group, it did not show statistically 


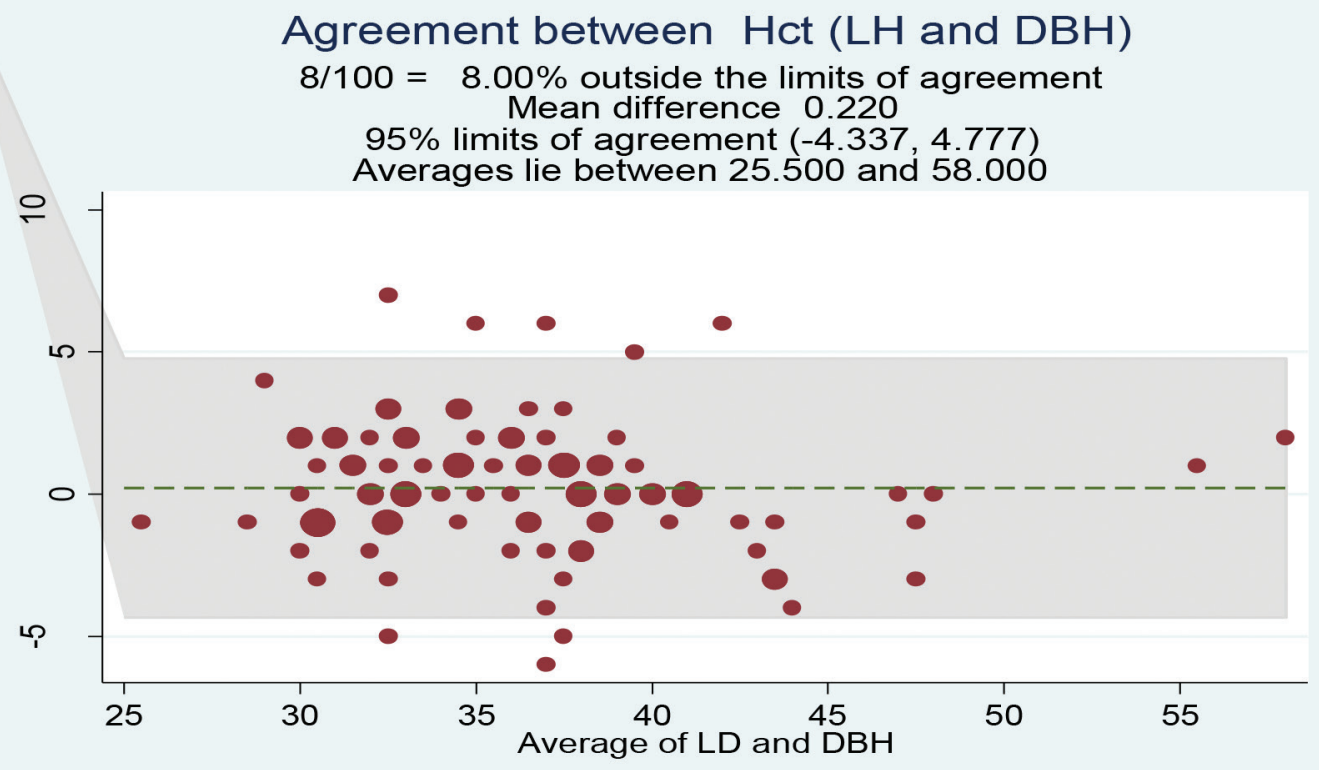

Fig. 7 Bland-Altman plot of hematocrit for the LH group was comparable with that of the DBH group. DBH, dry bound heparin; LH, liquid heparin.

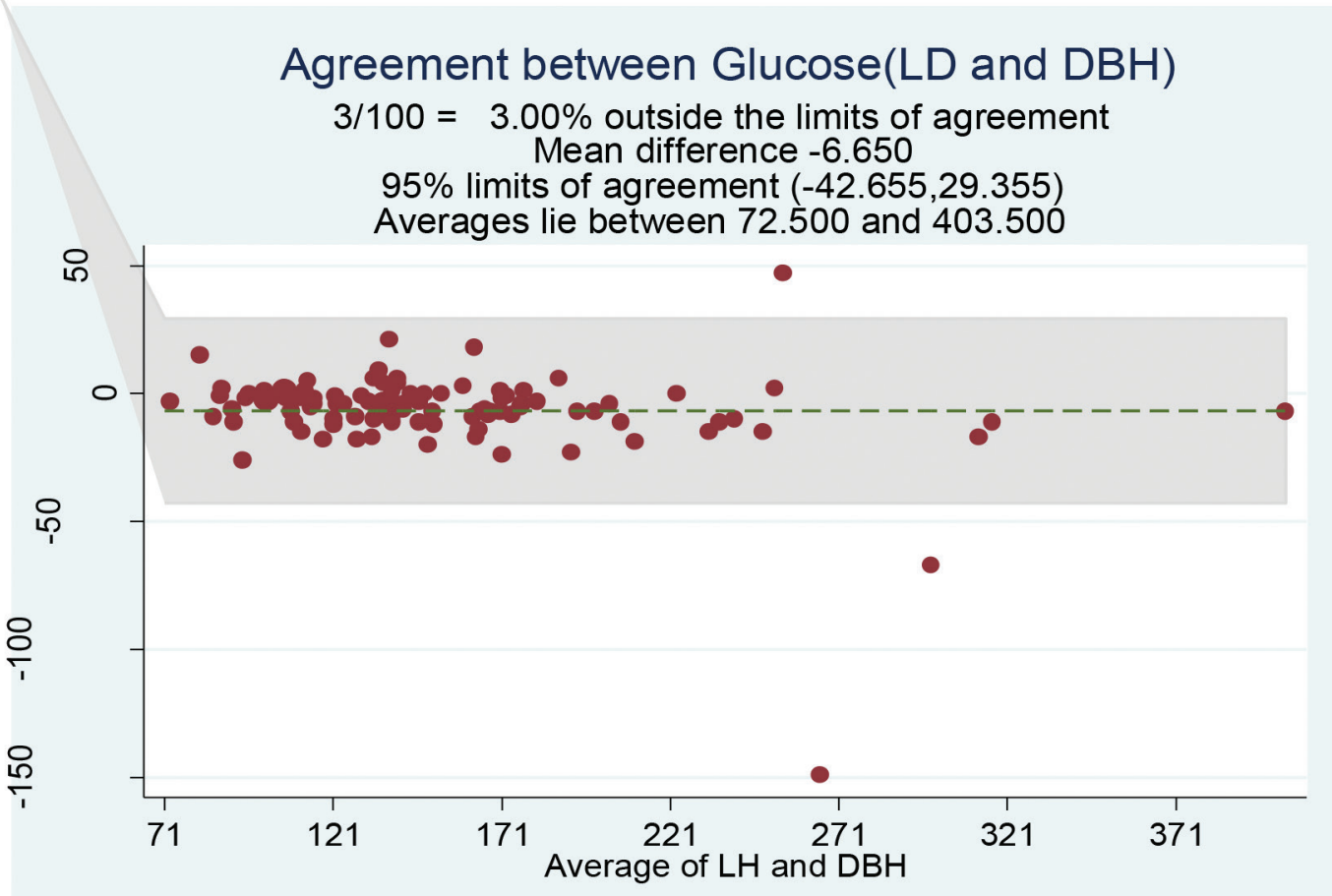

Fig. 8 Bland-Altman plot of glucose for the LH group was comparable with that of the DBH group. DBH, dry bound heparin; LH, liquid heparin.

relevant difference, and 5\% samples were beyond TEa limits. BE was surprisingly increased in the DBH group than the $\mathrm{LH}$ group but did not show statistical significance, with $7 \%$ samples beyond TEa limits. Delay in the analysis of BG sample can increase blood lactate levels due to anaerobic metabolism. ${ }^{18}$ Calatayud and Tenías studied the effect of time, temperature, and blood cell count on lactate levels in heparinized samples and showed that as delay time progresses for analysis at room temperature, parallel lactate levels rise. ${ }^{18}$ BG sample should be analyzed $<5$ minutes of collection to eliminate the unnecessary time-related error of lactate estimation. ${ }^{19}$ Chhapola et al demonstrated poor agreement between $\mathrm{LH}$ and $\mathrm{DBH}$ for the $\mathrm{BG}$ parameters $\mathrm{pCO}_{2}, \mathrm{pO}_{2}, \mathrm{HCO}^{3-}, \mathrm{Na}^{+}, \mathrm{K}^{+}$, and $\mathrm{Cl}^{-}$and thus are not comparable, but for $\mathrm{pH}$ and lactate, two study group syringes can be interchanged in pediatric ICU. ${ }^{20}$ But as per our study for all the parameters, DBH and LH syringes 
can be interchanged in adult cardiac surgical ICUs. Chhapola et al also studied the effects of varying volume of heparin on blood parameters and concluded that as the amount of heparin increases in sample syringe, the values of $\mathrm{pH}, \mathrm{pCO}_{2}, \mathrm{HCO}$, $\mathrm{Na}^{+}$, and $\mathrm{Hb}$ were decreased. ${ }^{21}$

A study by Hedberg et al with four different volume of samples compared commercial DBH syringes and showed that low-volumes samples were associated with significant errors in BG, electrolyte, and lactate measurements. ${ }^{22}$ Yip et al also got similar results: negative bias in positive ions were more seen in the pediatric population than adults. ${ }^{23}$

\section{Summary}

- Among respiratory parameters, $\mathrm{pO}_{2}(\mathrm{~mm} \mathrm{Hg})$ and $\mathrm{pCO}_{2}$ $(\mathrm{mm} \mathrm{Hg})$ showed wide LOA with acceptable sample beyond TEa of $8 \%$ for both, but $\mathrm{SaO}_{2} \%$ did not show any mean difference between two study groups, with nil sample number beyond TEa\% limits.

- $\mathrm{pH}$ was comparable between groups, with less mean bias and only $3 \%$ sample beyond TEa limits.

- Among the electrolyte, $\mathrm{Mg}^{2+}(\mathrm{mmol} / \mathrm{L}), \mathrm{K}^{+}(\mathrm{mmol} / \mathrm{L})$, and $\mathrm{Ca}^{2+}(\mathrm{mmol} / \mathrm{L})$ showed negligible mean difference and good agreement with 6,5 , and $5 \%$ of sample beyond TEa of limits, respectively, and $\mathrm{Cl}^{-}(\mathrm{mmol} / \mathrm{L})$ was the least affected one.

- Among the metabolic analytes, BE and lactate showed a difference between the two study groups, with 7 and $5 \%$ of sample beyond TEa limits, respectively.

- Hct showed minimal mean difference than $\mathrm{Hb}$, with sample beyond TEa limits of 8 and 3\%, respectively.

- Our study results did not show any clinical difference in LH and DBH syringes for BG analysis.

- None of the previous studies have proven the comparability between the LH and DBH syringes for all the parameters in $\mathrm{BG}$ readings until now.

- We believe that this result mainly depends on the quality of technics of sampling and titration while preparing $\mathrm{LH}$ syringes.

\begin{abstract}
Limitations
Although all our study results were comparable between both the LH and DBH groups with a negligible mean bias, there are some limitations in our study deign. It was restricted to the adult population only and included all types of adult cardiac surgical patients. Samples were collected from existing arterial lines after discarding the dead space volume. It was a single-center and small study. We did not compare our observed bias with desirable bias specifications given by Ricós al. ${ }^{24}$
\end{abstract}

\section{Conclusion}

Our study results have clearly showed that the LH and DBH syringes were comparable for all the BG parameters analyzed from arterial blood. We did not find any significant statistical difference among the various respiratory, metabolic, and electrolytes, which may be attributed to the appropriate manual preparation of LH syringes for sampling and of course the good technic of sampling, handling, and ready analyzing.

\section{Funding \\ None. \\ Conflict of Interest \\ None.}

\section{References}

1 Baird G. Preanalytical considerations in blood gas analysis. Biochem Med (Zagreb) 2013;23(1):19-27

2 Higgins $C$. The use of heparin in preparing samples for bloodgas analysis. MLO Med Lab Obs 2007;39(10):16-18, 20, quiz 22-23

3 National Committee for Clinical Laboratory Standards. Procedures for Collection of Arterial Blood Specimens; Approved Standard- Fourth Edition. NCCLS: Wayne, PA; 2004

4 Küme T, Sişman AR, Solak A, Tuğlu B, Cinkooğlu B, Coker C. The effects of different syringe volume, needle size and sample volume on blood gas analysis in syringes washed with heparin. Biochem Med (Zagreb) 2012;22(2):189-201

5 World Health Organization. Use of anticoagulants in diagnostic laboratory investigations. https://apps.who.int/iris/handle/10665/65957. Accessed January 31, 2020

6 Gruber M, Spaeth R, Bechmann V. Heparin release is insufficient in syringes with platelets as heparin source. Clin Chim Acta 2008;395(1-2):187

7 Orazio PD. Effects of blood clots on measurements of $\mathrm{pH}$ and blood gases in critical care analyzers. Point Care 2011;10:186-188

8 Biswas CK, Ramos JM, Agroyannis B, Kerr DN. Blood gas analysis: effect of air bubbles in syringe and delay in estimation. Br Med J (Clin Res Ed) 1982;284(6320):923-927

9 Hamilton RD, Crockett RJ, Alpers JH. Arterial blood gas analysis: potential errors due to the addition of heparin. Anaesth Intensive Care 1978;6(3):251-255

10 Ordog GJ, Wasserberger J, Balasubramaniam S. Effect of heparin on arterial blood gases. Ann Emerg Med 1985;14(3):233-238

11 Hutchison AS, Ralston SH, Dryburgh FJ, Small M, Fogelman I. Too much heparin: possible source of error in blood gas analysis. Br Med J (Clin Res Ed) 1983;287(6399):1131-1132

12 Shin CS, Chang CH, Kim JH. Liquid heparin anticoagulant produces more negative bias in the determination of ionized magnesium than ionized calcium. Yonsei Med J 2006;47(2):191-195

13 Chantler J, Cox DJ. Self-prepared heparinized syringes for measuring ionized magnesium in critical care patients. $\mathrm{Br} \mathrm{J}$ Anaesth 1999;83(5):810-812

14 Toffaletti J. Use of novel preparations of heparin to eliminate interference in ionized calcium measurements: have all the problems been solved? Clin Chem 1994;40(4):508-509

15 Chhapola V, Kanwal SK, Sharma R, Kumar V. A comparative study on reliability of point of care sodium and potassium estimation in a pediatric intensive care unit. Indian J Pediatr 2013;80(9):731-735

16 Morimatsu H, Rocktäschel J, Bellomo R, Uchino S, Goldsmith D, Gutteridge G. Comparison of point-of-care versus central laboratory measurement of electrolyte concentrations on calculations of the anion gap and the strong ion difference. Anesthesiology 2003;98(5):1077-1084

17 Sandler P, Goldstein LN. The effect of different forms of heparin on point-of-care blood gas analysis. S Afr Med J 2018;108(3):224-229 
18 Calatayud O, Tenías JM. Effects of time, temperature and blood cell counts on levels of lactate in heparinized whole blood gas samples. Scand J Clin Lab Invest 2003;63(4):311-314

19 Knowles TP, Mullin RA, Hunter JA, Douce FH. Effects of syringe material, sample storage time, and temperature on blood gases and oxygen saturation in arterialized human blood samples. Respir Care 2006;51(7):732-736

20 Hedberg P, Majava A, Kiviluoma K, Ohtonen P. Potential preanalytical errors in whole-blood analysis: effect of syringe sample volume on blood gas, electrolyte and lactate values. Scand J Clin Lab Invest 2009;69(5):585-591

21 Chhapola V, Kumar S, Goyal P. Is liquid heparin comparable to dry balanced heparin for blood gas sampling in intensive care unit? Indian J Crit Care Med 2014;18(1):14-20
22 Chhapola V, Kumar S, Goyal P, Sharma R. Use of liquid heparin for blood gas sampling in pediatric intensive care unit: a comparative study of effects of varying volumes of heparin on blood gas parameters. Indian J Crit Care Med 2013;17(6):350-354

23 Yip PM, Chan MK, Zielinski N, Adeli K. Heparin interference in whole blood sodium measurements in a pediatric setting. Clin Biochem 2006;39(4):391-395

24 Ricós C, Alvarez V, Cava F, et al. Current databases on biological variation: pros, cons and progress. Scand J Clin Lab Invest 1999;59(7):491-500 